\title{
Design, Simulation and Implementation High DC- DC Converter with 1-Phase Inverter Feeding Load from a Single Photovoltaic Panel
}

\author{
Khalid Badr Yas ${ }^{1}$ \\ khalidbaderyass@gmail.com \\ Ministry of Education, Iraq. Baghdad ${ }^{1}$
}

\begin{abstract}
A DC/DC converter is used in a traditional single-phase two-stage gridconnected micro-inverter for photovoltaic (PV) applications to acquire the most DC power from the PV module. The rising voltage of the PV module to a grid voltage level is limited to a specified value in this inverter. Furthermore, the two-stage inverter is less efficient due to the lack of separation between the input and output. To supply an alternating current (AC) to the load, a single-stage Push-Pull PV micro-inverter was designed, simulated, and constructed in this research. To keep the produced power as high as possible, a microcontroller PIC 16F877A is used to track the highest power point of the panel and compute the appropriate pulse width of the converter. Sinusoidal pulse width modulation is employed for this purpose. The incremental conductance algorithm and maximum power point tracking (MPPT) technique are implemented using the PIC microcontroller. The PV module is tested using Matlab/Simulink software under varied solar irradiance (G) and ambient temperature ( $\mathrm{T}$ ) conditions. Experimentation results from a lab prototype are also given. The prototype will become a system that feeds a single-phase AC load with a clean sinusoidal current waveform from a single panel. The key advantage of this model is that it includes a real microcontroller, just like in real life, so that the MPPT algorithm code used in simulation will be used in real life.
\end{abstract}

Keywords: Photovoltaic Panel, Push-Pull DC-DC Converter, Micro-Inverter, Incremental Conductance, Matlab Simulink, Microcontroller.

\section{Introduction}

Solar energy will have a huge impact on its long-term benefits, which will be widely spread throughout the world because it is clean, inexhaustible, an independent resource, and its development is affordable because it is climate-friendly and an ideal power source for energydeficient areas, making it advantageous [1]. There are many application fields for the conversion of solar energy into electrical energy such as vehicular, naval, residential, aircraft, and space applications [1-3]. As a result, solar energy is likely to play a significant part in global electric power generation in the next decades. A photovoltaic (PV) system can be used to harvest this energy. PV systems can be used either as stand-alone systems or in conjunction with the utility grid. In this study, stand-alone PV systems are designed to function independently of the electric utility grid, and they are often planned and sized to serve specific DC and/or AC electrical needs. Only a PV array may be used to power these systems. A directcoupled system, in which the DC output of a PV module or array is directly connected to the converter, is the most basic sort of stand-alone PV system. Because direct-coupled systems need electrical energy storage (batteries), the load functions only during daylight hours, making 
them ideal for typical applications like ventilation fans, water pumps, and small circulation pumps for solar thermal water heating systems [4-5]. The rapidly falling cost of stand-alone PV modules, advances in power electronics, and government incentives for PV systems make it critical that PV system penetration on the utility grid continues to rise, particularly on low and medium voltage grids [6]. Nowadays, more and more complex PV systems are being studied for designing and implementation of efficient PV system strategies. The input voltage to DC/DC converters varies substantially in regulated switch mode power supplies, notably in the case of PV supply sources due to unpredictable and rapid variations in solar irradiation and cell operating temperature. Several switching system connection topologies have been presented [7] with the goal of achieving the appropriate voltage level for specific applications such as pumps, motors in general, and power supply at various times of the day. The application in this case is to provide power to the load. This is accomplished by employing an inverter to convert the DC electric power generated by the PV array to AC electricity. The load is supplied with the inverter's output power. The (PV) array feeds a power optimizer, which is a DC/DC converter. It will supply its output power to the load or inverter. The power optimizers can extract maximum power from PV systems by continuously tracking the maximum PowerPoint. This is done by individually tuning the performance of the panel through (MPP). A power optimizer is ideal for treating PV arrays during the variation in irradiance and temperature. Maximum power point tracking is a technique usually utilized with a photovoltaic (PV) array system to track the point of maximum power. This is done by adjusting the pulse width of the DC/DC converter's electronic switch, to reach the maximum power point at different conditions [8-9]. In this work, a step-up (Push-Pull) DC/DC converter is used to fulfill the requirement of the inverter. It consists of five components: transformer, electronic switch, diode, and an input and output capacitor. The choice of the (DC/DC) Push-Pull converter configuration provides the lowest cost and the higher efficiency [10]. The maximum power point tracker has numerous algorithms such as incremental conductance, perturb and observe method, constant voltage, and constant current, etc. The selection between them is based on the operating conditions of the PV and the advantages of one of them due to many requirements and conditions. The incremental conductance algorithm is the most often utilised because of its great adaptability and accuracy throughout all seasons [11]. It is based on changes in light and temperature. On the power curve of a photovoltaic (PV) array, the MPP is found at the zero slope point. MPP has a negative on the right and a positive on the left. The terminal voltage of a photovoltaic (PV) array is always adjusted according to the MPP [12]. The (PV) array voltage and current must be monitored to estimate the conductance and incremental conductance. The maximum power point (MPP) is tracked in real-time using a microcontroller in this paper to solve the aforementioned drawbacks. A microcontroller has the advantage of not oscillating close to MPP. This type of control is only found in the Push-Pull converter, which uses a high-frequency transformer to create galvanic isolation between the input and output sides as well as a high conversion ratio. The PV module has been modeled and simulated based on the one-diode PV model using Matlab/Simulink software. The system to be simulated and implemented is shown below. It is composed of three main parts; the first part is the photovoltaic (PV) panel, which is intended to convert solar energy to electric energy. The second part is represented by the DC to DC converter triggered by using the Max-mum Power Point Tracker (MPPT) algorithm. Because photovoltaic (PV) arrays have a poor efficiency, the MPPT is used to extract maximum power and improve efficiency under various conditions. The third part is a 1-phase inverter switched by the sinusoidal pulse width modulation (SPWM) technique to provide sinusoidal voltages supplying the 1-phase electric load. 


\section{System Description}

\subsection{One-diode PV Cell Model}

A PV cell model is represented by the corresponding circuit in Fig 1. A one-diode model [13] is another name for this concept. The output voltage and current of PV are Vpv and Ipv, which are coupled in parallel and series, respectively. Is is the diode saturation current, and Isource is the photocurrent source. The basic equation that represents the I-V characteristic of the ideal $\mathrm{PV}$ cell is [14] derived from semiconductor theory.

$\mathrm{I}_{\text {source }}-\mathrm{I}_{\mathrm{d}}-\frac{V_{d}}{R_{p}}-\mathrm{I}_{\mathrm{p}}=0$

$\mathrm{I}_{\mathrm{d}}=\mathrm{I}_{\mathrm{s}}\left[\exp \left(\frac{q V_{d}}{N k t}\right)-1\right]$

$\mathrm{V}_{\mathrm{PV}}=\mathrm{V}_{\mathrm{d}}-\mathrm{R}_{\mathrm{se}} . \mathrm{I}_{\mathrm{PV}}$

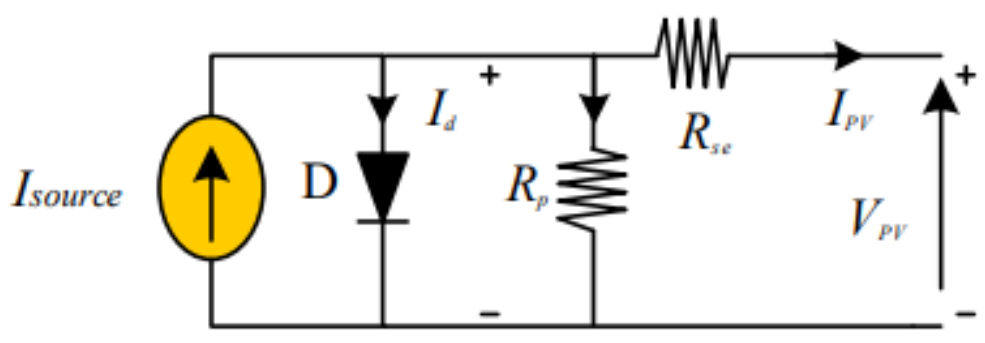

Fig. 1. Equivalent circuit of one-diode model for PV cell.

\subsection{MPPT}

As demonstrated in the flowchart in Fig 2, the incremental conductance method is utilised to change the duty cycle of the converter to follow the MPP. The I_C's algorithm has many topologies, but all that depends on the $\Delta V$ and $\Delta I$. The naming came from the term $(\Delta I / \Delta V)$ which is known as incremental conductance [15]. This value makes the algorithm go in the right direction and achieving the goal at which $\{(\Delta P / \Delta V)=0\}$ means reaching the maximum power point, as seen in Fig 3. The I-C algorithm catches the maximum power point exactly and still observing the system by observing the $\Delta V$ and $\Delta I$, if they have any changes, then it will repeat the procedure to catch the maximum power point again. After calculating the $\Delta V$ and $\Delta I$ through the new condition, if the $\Delta V \neq 0$ this means the algorithm point is somewhere, but not on biggest power point, so the algorithm looking again at the sign of the new $(\Delta P / \Delta V)$, whether it is positive or negative for pursuing the right direction to reach the MPP again.

Assuming it catching up the maximum power point (MPP) at certain weather condition if the condition change suddenly the $\Delta V$ not change and still equal to zero, but the $\Delta I$ has greatly changed, that makes the algorithm to operate again and so on. The magnitude of the increment controls how quickly the MPP is tracked [16]. It is possible to increase the increment size, but 
at the expense of accuracy [17]. Figure 4 depicts the algorithm's responsiveness to changing weather conditions.

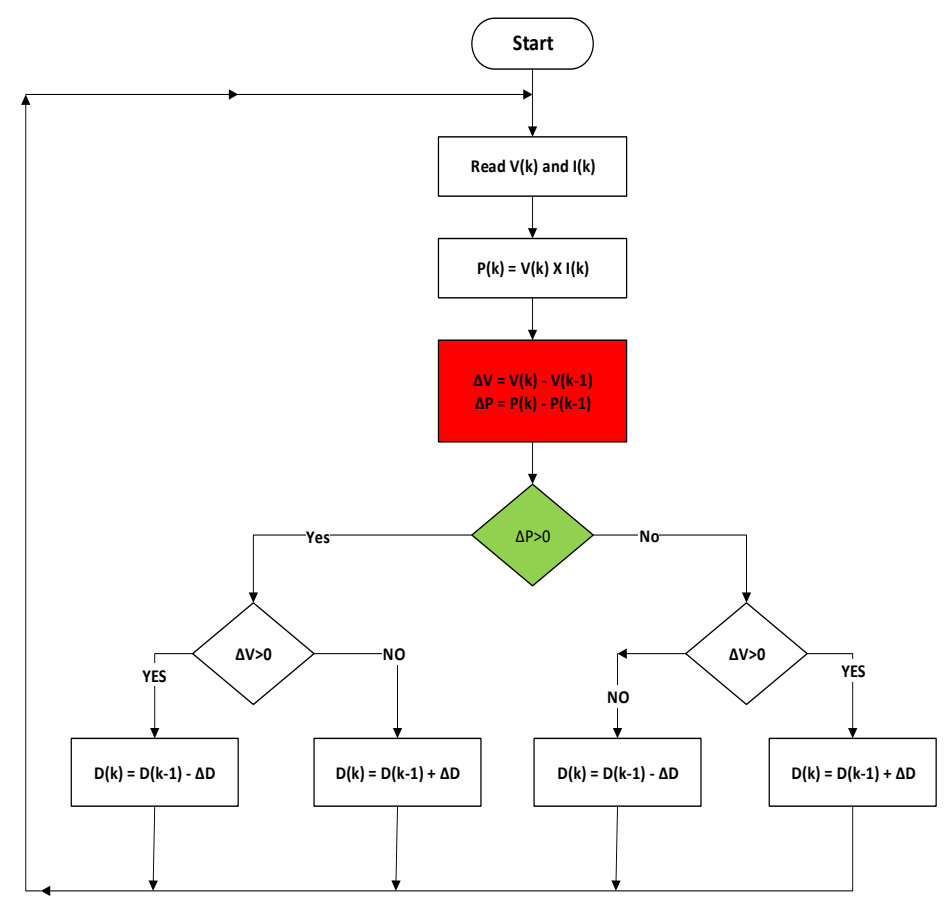

Fig 2. I_C's algorithm.

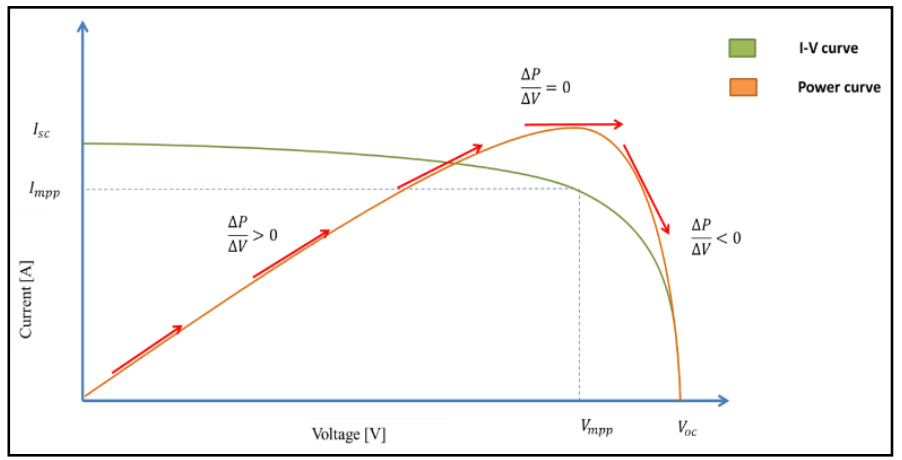

Fig 3. Operation of I_C Algorithm. 


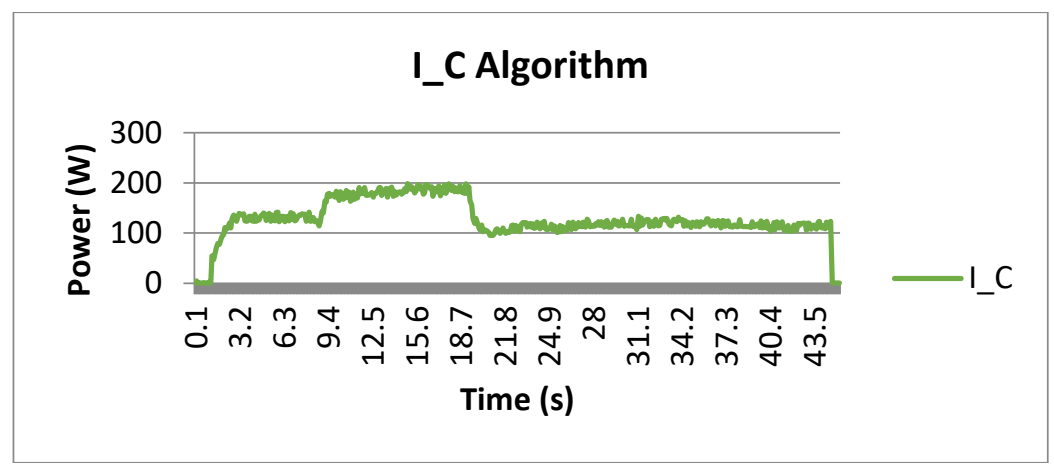

Fig 4. I_C Response

\subsection{DC/DC Converter}

A step-up DC/DC Push-Pull converter must be utilised to feed a 1-phase, $50 \mathrm{~Hz}, 220 \mathrm{~V}$ AC load from low voltage (PV) panels, as shown in Fig. 5. This converter feeds the 1-phase inverter by the required voltage. The DC/DC converters are widely used to step up the DC voltage or to regulate (PV) array voltage. The input of these converters is a fluctuated DC voltage, which is supplied by the PV panels. So the mean DC output voltage should be adjusted to be equal to the required value. The quantity of energy absorbed from the PV and given to the inverter is continuously adjusted to accomplish output voltage regulation in the DC/DC converter. The maximum power point tracker (MPPT) algorithm adjusts the duty cycle for these two essential processes of energy absorption and injection.

The output from PIC is a PWM signal with a variable duty cycle ratio that is applied to the main IGBT through the optocoupler. Two optocouplers are used for the two IGBTs $\mathrm{SAC}_{1}$ and $\mathrm{SAC}_{2}$. The PV module voltage and current are sensed using a voltage divider and a current sensor, respectively. The signals of these sensors are fed to the microcontroller to implement the MPPT algorithm. A bank of input electrolytic capacitors consists of $2400 \mu \mathrm{F}$ connected across the PV input side.

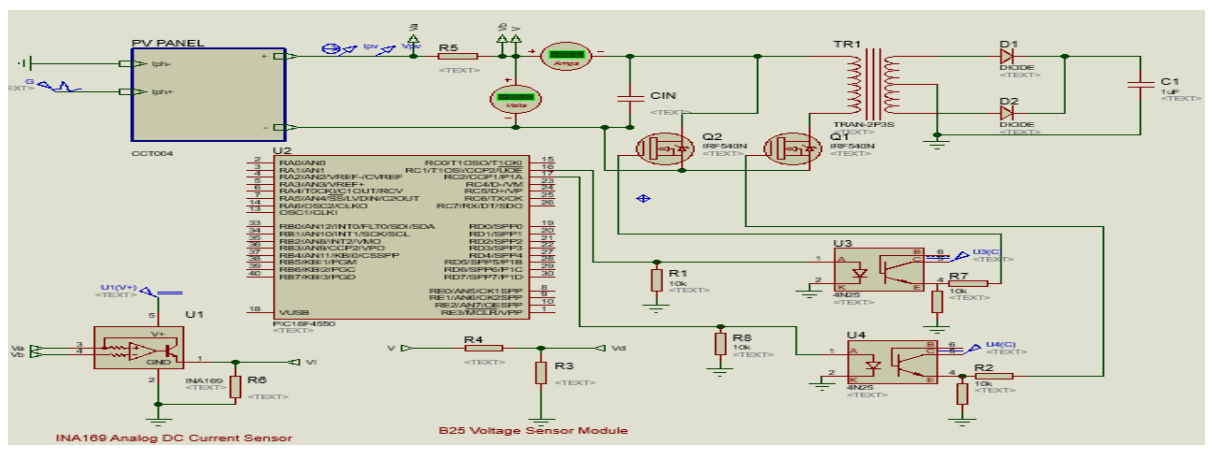

Fig 5. The Power Optimizer Simulation Typical Connection. 


\subsection{Inverter}

The main purpose of a DC/AC full-bridge converter (inverter) is to produce alternating voltage and current waveforms from a DC power source. These types of power waveforms are found into many methodologies according to the load requirement. Hence, the output waveform parameters like magnitude and frequency can be controlled. Inverters can be divided into two types: voltage source inverter (VSI) and current source inverter (CSI). The voltage source inverters are most commonly used with a V/f control of Ac load, as seen in Fig 6. The PWM signals of the IGBTs generated by the microcontroller. The gate driver is implemented using an IR2110 integrated circuit. These drives are ideally suited for driving power IGBTs and used in inverter applications.

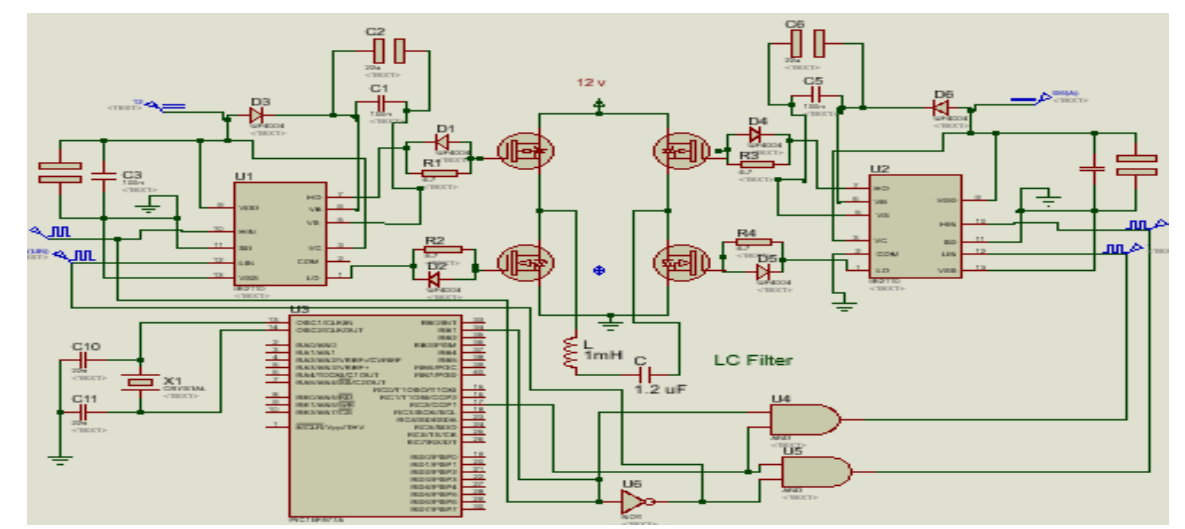

Fig. 6. Circuit of a Power Inverter with an LC Filter.

\subsection{Microcontroller Based SPWM}

This system's basic control circuit is a microcontroller that was designed to generate two digital SPWMs that are 180 degrees apart. The SPWM switching technique is used to provide a clean sine wave. This approach uses the same switching pattern as the DC-to-AC two-leg inverter. The SPWM is a dependable method. It's used in a variety of power electronics applications, including motor drivers, UPS systems, and renewable energy systems. Following the original sine wave amplitude, SPWM switching techniques are described as constant amplitude pulses with a variable duty cycle for each period. The most frequent way to make this signal is to compare a sinusoidal and a triangular waveform, as seen in Fig 7. We use a peripheral interface controller (PIC) microcontroller to replace the traditional technique in this study. Using the built-in PWM module, the microcontroller can stack commands to generate the required pulse width modulation waveform. Using the PIC16F877A system, the microcontroller generates a variable pulse width modulation signal that regulates the applied voltage on the gate drive. The microcontroller is simple and adaptable, allowing for real-time control algorithm changes without requiring any hardware changes. This inverter could be used in a stand-alone balanced load system or a grid-connected system powered by a photovoltaic panel. 


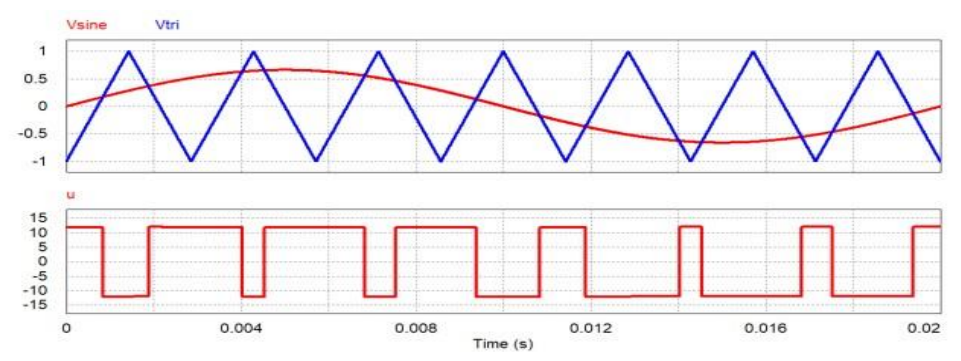

Fig 7. SPWM Generational Method.

Table 1. illustrates all of the criteria that were considered as well as the final design $[18,19]$.

\begin{tabular}{|c|c|c|}
\hline NO. & Parameter & Value \\
\hline 1 & Converter parameters & \\
\hline 2 & $V_{p v}$ & $34-38 \mathrm{~V}$ \\
\hline 3 & $I_{p v}$ & $8 \mathrm{~A}$ \\
\hline 4 & $P_{\text {out }}$ & $290 \mathrm{~W}$ \\
\hline 5 & $D_{\max }$ & 0.5 \\
\hline 6 & $f_{s}$ & $30 \mathrm{kHz}$ \\
\hline 7 & $C_{\text {in }}$ & $2400 \mathrm{uF}$ \\
\hline 8 & $N$ & 12 \\
\hline 9 & $V_{\text {out }}$ & $640 \mathrm{~V}$ \\
\hline 10 & $\eta$ & 0.85 \\
\hline 11 & Transformer design parameters & \\
\hline 12 & $N_{p}$ & 7 \\
\hline 13 & $N_{S}$ & 84 \\
\hline 14 & $P I V$ & $800 \mathrm{~V}$ \\
\hline 15 & Inverter Parameters & \\
\hline 16 & IGBT's PIV & $1800 \mathrm{~V}$ \\
\hline 17 & Filter Parameters & \\
\hline 18 & $\mathrm{~L}$ & $1 \mathrm{mH}$ \\
\hline 19 & $\mathrm{C}$ & 1.2 uf \\
\hline
\end{tabular}

\section{Simulation Results}

The simulation results, as shown in Figs below show the $\mathrm{P}-\mathrm{V}$ and $\mathrm{I}-\mathrm{V}$ characteristics of the PV module for the one-diode model. The PV module has been tested by Matlab/Simulink as seen in figures 8 and 9 based on its datasheet parameters. To show the effects of the solar irradiation and ambient temperature on PV module characteristics, they illustrate and verify the nonlinear PV and IV PV output characteristics module. The PV module is tested for various solar irradiation and ambient temperature. To demonstrate the influence degree of each parameter on the characteristics of the PV module, the solar irradiation and ambient temperature should be varied independently. In addition, to demonstrate the impact of ambient temperature and solar irradiance on PV module properties. They demonstrate and verify the non-linear IV 
and PV of PV output characteristic, and it has been tested under different solar irradiation and temperature. The solar radiation and ambient temperature must be changed autonomously to show the effect degree of each parameter on the characteristics of the PV module. Figs 10 and 11 show the IV and PV variations of one-diode model under varying temperature levels $(0,25$, $55^{\circ} \mathrm{C}$ ) and constant irradiation $\left(1000 \mathrm{~W} / \mathrm{m}^{2}\right)$. When the temperature of the PV array is raised at constant solar irradiation, the voltage of the PV array falls, and the current rises, resulting in a decrease in the PV array's generated power.

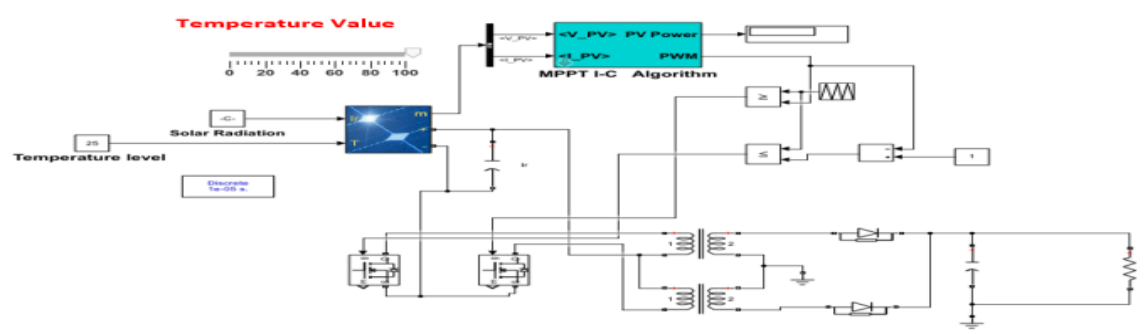

Fig 8. Simulated of the photovoltaic system under fixed irradiation and various temperature.

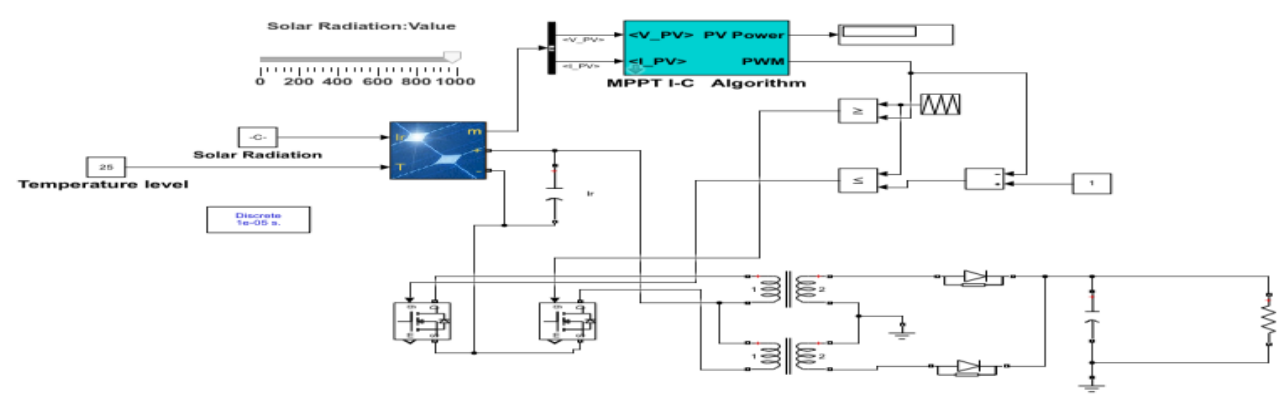

Fig 9. Simulated of the photovoltaic system under fixed temperature and various irradiation.

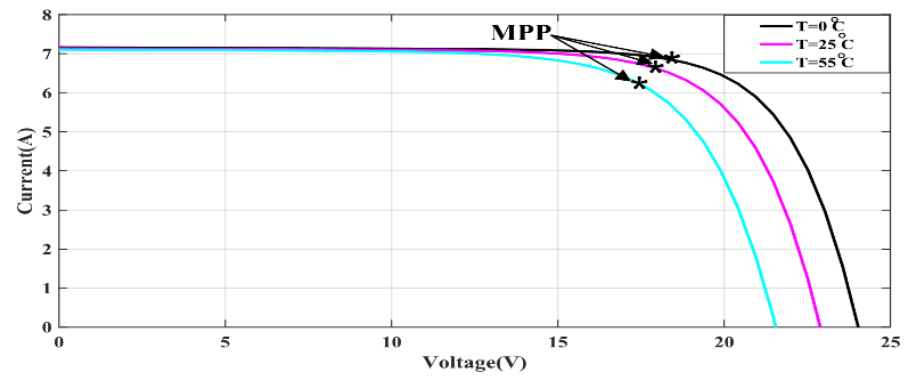

Fig 10. I-V curve under fixed irradiation and various temperature. 


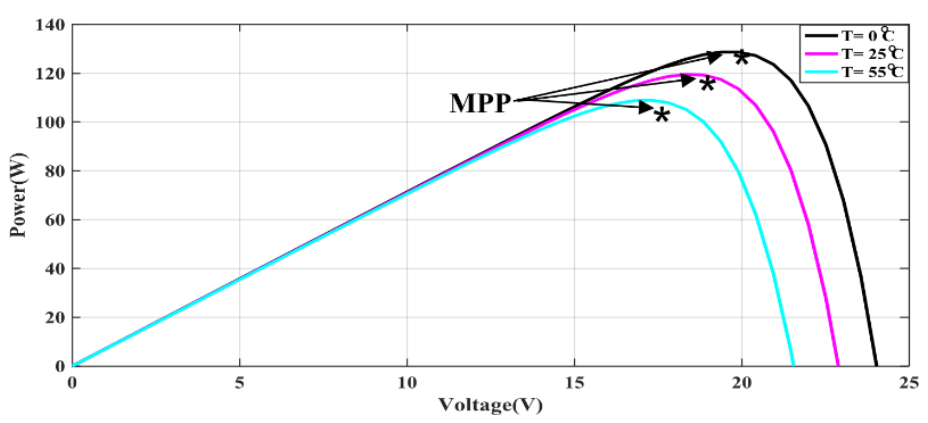

Fig 11. P-V curve under constant irradiation and various temperature.

The I-V and P-V characteristics of the one-diode model are shown in Figs 12 and 13 for different irradiation levels $\left(1000,800,600 \mathrm{~W} / \mathrm{m}^{2}\right)$ and constant temperature $\left(25^{\circ} \mathrm{C}\right)$. The results displayed in the figures below show that when solar radiation is reduced from a constant temperature of $25^{\circ} \mathrm{C}$, the PV array's voltage drops from $\mathrm{V}$, the current drops, and the PV array's generated power drops.

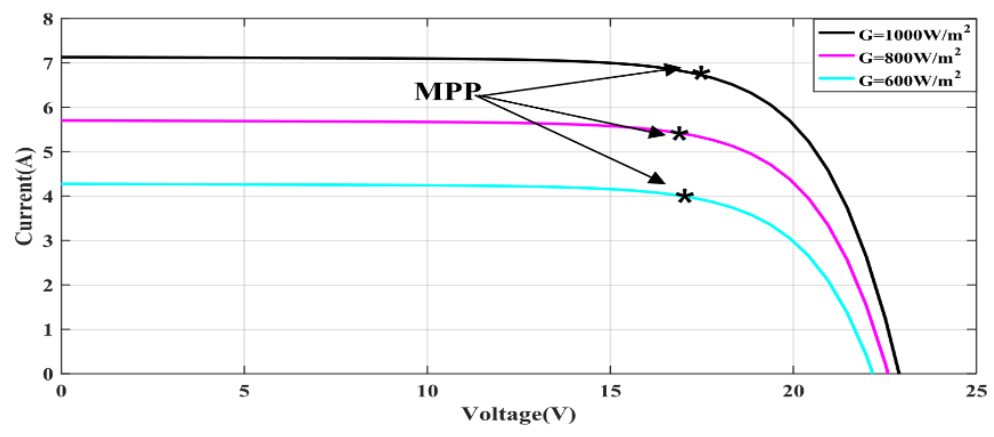

Fig 12. I-V curve under varied irradiation and constant temperature.

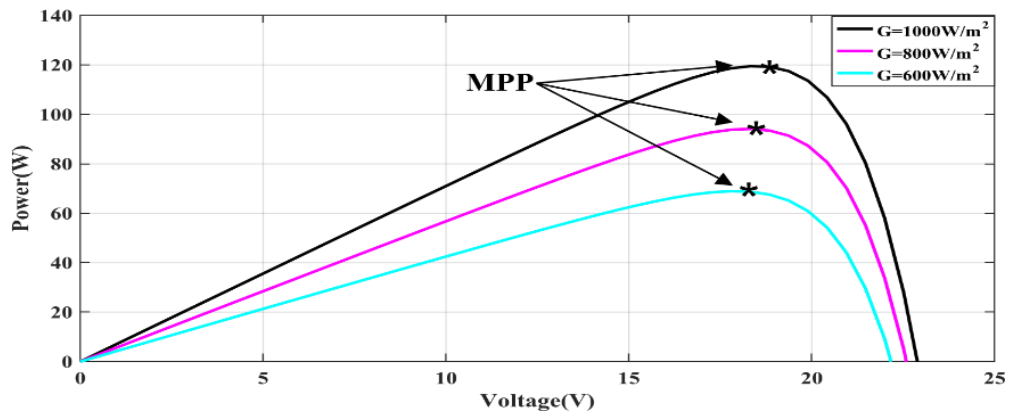

Fig 13. P-V curve under varied irradiation and constant temperature. 


\section{Experimental Implementation}

The hardware power stage circuit for the proposed system is implemented using the design specification above. The voltage of the PV module has a range between $34-38 \mathrm{~V}$ that is connected to the input terminals DC/AC inverter via Pull-Pull converter power circuit. The practical testbed of the converter is illustrated in Fig 14. While the practical inverter circuit implementation is in Fig 15. The results without and with filter are shown in Fig.16 and Fig. 17 respectively. The output voltage of the inverter is $220 \mathrm{~V}$.

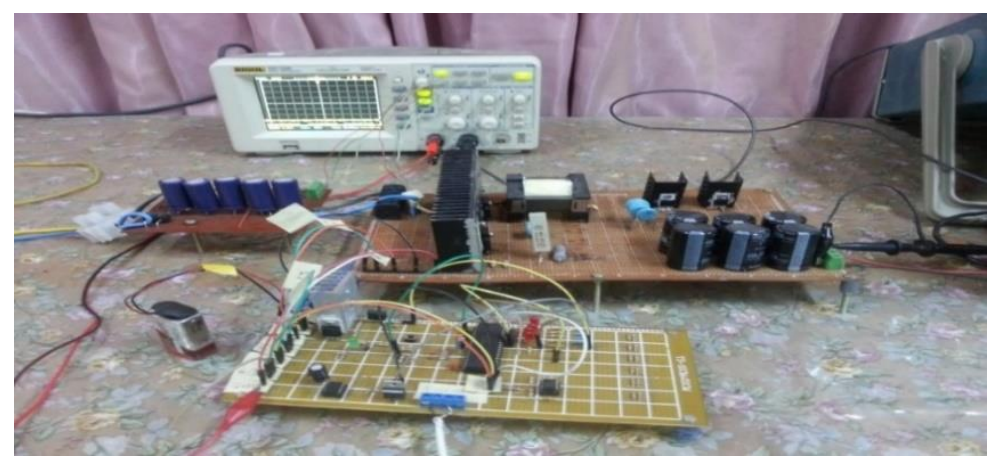

Fig 14. Practical Prototype of the Converter Power Circuit.

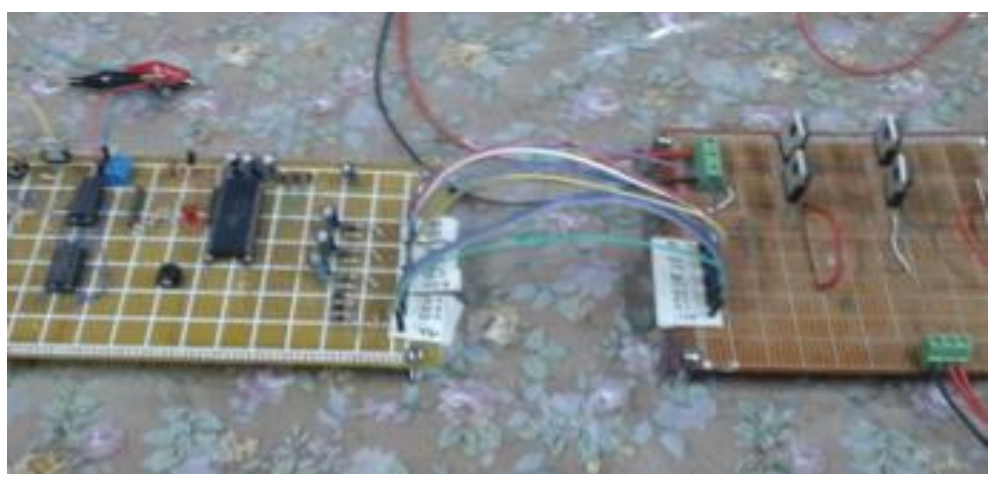

Fig 15. Inverter Practical Circuit. 


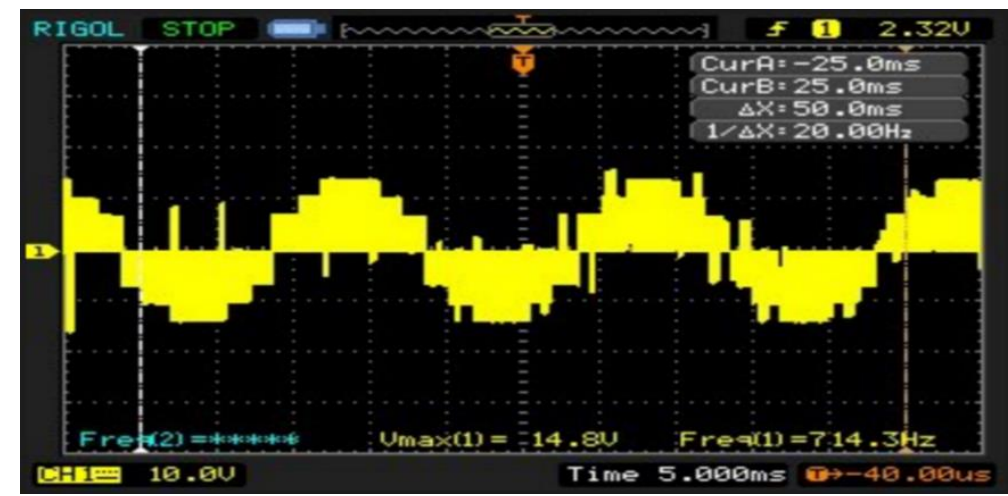

Fig 16. Output Sinusoidal Current Signal without Filter 24 Volt DC Input.

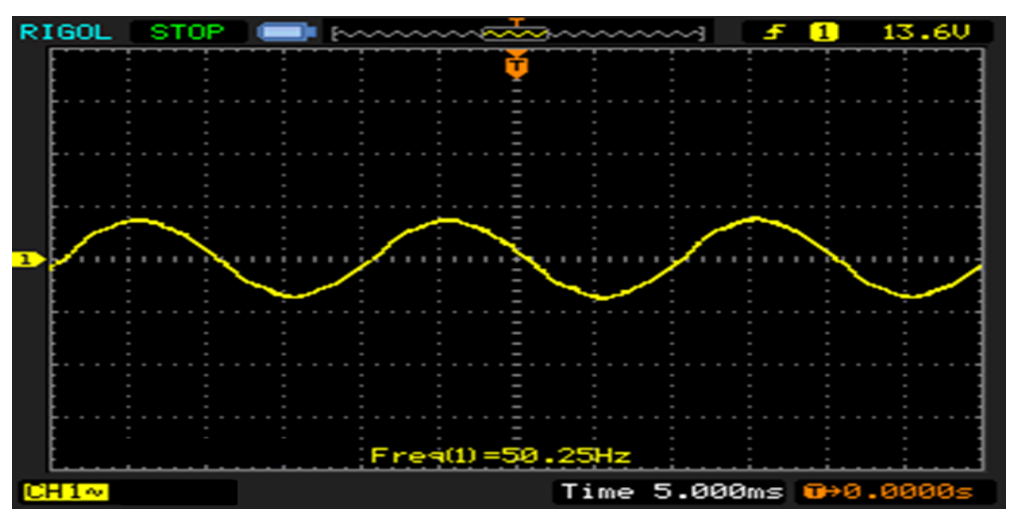

Fig 17. Filter and 540 Volt DC Input Output Sinusoidal Voltage Signal Across the Resister Load (Current waveform).

\section{Conclusion}

In this paper, a single-phase Push-Pull PV micro-inverter operating in DCM has been designed and implemented to feed alternating current to the load from a $250 \mathrm{~W}$ photovoltaic module. The PV module has been modeled and simulated based on the one-diode PV model using Matlab/Simulink software. DC/DC at $30 \mathrm{kHz}$ The PV array's voltage is raised from PV DC at full power to $640 \mathrm{~V} \mathrm{DC}$ using a Push-Pull converter. The MPPT controller uses the Incremental Conductance (I-C) technique to optimise the duty ratio. The duty ratio of this MPPT system is automatically varied to extract the most power. The inverter device will handle the DC to AC conversion. The output power optimizer voltage (up to 640 volts) will be used to generate 1-phase 220 volts at $50 \mathrm{~Hz}$. Furthermore, all of the plans are put into practise in the lab.

\section{References}

[1] B. Hachim, D. Dahlioui, and A. Barhdadi, "Electrification of Rural and Arid Areas by Solar Energy Applications," 2018 6th International Renewable and Sustainable Energy Conference (IRSEC), Rabat, Morocco, 2018, pp. 1-4, doi: 10.1109/IRSEC.2018.8702978.

[2] R. Dqg et al., "Control and implementation of a standalone solar photo-voltaic hybrid system." pp. 1-8, Page 1 of 8 2015-IACC-03932015. 
[3] L. An and D. D. C. Lu, "Design of a single-switch DC/DC converter for a PV-battery-powered pump system with PFM+PWM control,’IEEE Trans. Ind. Electron., vol. 62, no. 2, pp. 910-921, 2015.

[4] W. Priyono, D. F. Wijayan and E. Firmansyah, "Study and Simulation of a Hybrid Stand-alone PV System for Rural Telecomunications System," 2018 3rd International Conference on Information Technology, Information System and Electrical Engineering (ICITISEE), Yogyakarta, Indonesia, 2018, pp. 418-422, doi: 10.1109/ICITISEE.2018.8721000.

[5] "IEEE Recommended Practice for Sizing Lead-Acid Batteries for Stand-Alone Photovoltaic (PV) Systems," in IEEE Std 1013-2019 (Revision of IEEE Std 1013-2007), vol., no., pp.1-50, 20 Sept. 2019, doi: 10.1109/IEEESTD.2019.8845030.

[6] Z. M. Salameh, "on the Performance of a Pv-Powered VolumetricWater Pump," IEEE Transactions on Energy Conversion, vol. 5, no. 4, December 1990.

[7] S. Sukatjasakul and S. Po-Ngam, "The micro-grid connected single-phase photovoltaic inverter with simple MPPT controller," 2017 International Electrical Engineering Congress (iEECON), Pattaya, 2017, pp. 1-4, doi: 10.1109/IEECON.2017.8075751.

[8] L. Callegaro, M. Ciobotaru, J. E. Fletcher, P. A. Rios and D. J. Pagano, "Design of cascaded control loop for solar power optimizer based on a buck-boost converter," 2016 IEEE 2nd Annual Southern Power Electronics Conference (SPEC), Auckland, 2016, pp. 1-6, doi: 10.1109/SPEC.2016.7846136.

[9] K. B. and T. Morey, "Switching Power Supply Design Third Edition. Third Edition, McGraw-Hill Companies", New York, 2011.

[10] M. H. Rashid, "POWER ELECTRONICS Academic Press Series in Engineering". 2001.

[11] M. Seyedmahmoudian, B. Horan, R. Rahmani, A. M. T. Oo, and A.Stojcevski, "Efficient photovoltaic system maximum power point tracking using a new technique," Energies, vol. 9, no. 3, pp. 1-18, 2016.

[12] M. Seyedmahmoudian et al., "State of the art artificial intelligence-based MPPT techniques for mitigating partial shading effects on PV systems - A review," Renew. Sustain. Energy Rev., vol. 64, pp. 435- 455, 2016.

[13] V. K. Viswambaran, A. Ghani and E. Zhou, "Modelling and simulation of maximum power point tracking algorithms \& review of MPPT techniques for PV applications," 2016 5th International Conference on Electronic Devices, Systems and Applications (ICEDSA), Ras Al Khaimah, 2016, pp. 1-4, doi: 10.1109/ICEDSA.2016.7818506.

[14] Y. Hsieh, L. Yu, T. Chang, W. Liu, T. Wu and C. Moo, "Parameter Identification of One-Diode Dynamic Equivalent Circuit Model for Photovoltaic Panel," in IEEE Journal of Photovoltaics, vol. 10, no. 1, pp. 219-225, Jan. 2020, doi: 10.1109/JPHOTOV.2019.2951920.

[15] P. K. Vineeth Kumar and K. Manjunath, "Analysis, design and implementation for control of noninverted zeta converter using incremental conductance MPPT algorithm for SPV applications," 2017 International Conference on Inventive Systems and Control (ICISC), 2017, pp. 1-5, doi: 10.1109/ICISC.2017.8068662.

[16] R. A. Messenger and J. Ventre, "Photovoltai Systams Engineering," No claim to original U.S. Government works International Standard Book Number 0-8493-1793-2 Library of Congress Card Number 2003053063, ISBN 0-203-50629-4 Master e-book ISBN, 2005.

[17] T. K. Ghosh and M. A. Prelas, "Energy Resources and Systems", Volume 2, vol. 1. 2009.

[18] keng chin wu Pulse Width Modulated DC/DC Converters

[19] C. W. T. Mclyman, "Transformer and Inductor Design Handbook," Third Edition, Revised and Expanded, ISBN:0-8247-5393-3, California, U.S.A, 2004. 